\title{
LA MODERNIDAD DESPOBLADA EN EL CINE DOCUMENTAL CHILENO: 1903-1933
}

The unpopulated modernity in documentary film: 1903-1933

\author{
Pablo Corro Penjean*
}

\section{RESUMEN}

El autor propone la relación estética e ideológica paradojal o contradictoria, que se advierte en documentales del cine chileno del periodo 1903-1933, entre la intención de acreditar la modernidad material e institucional de Chile, particularmente de su capital, Santiago, y de algunos enclaves industriales, y la figuración despoblada de los emplazamientos dramáticos, de los espacios públicos expuestos en tales registros.

Palabras clave: Cine documental chileno, modernidad, despoblamiento.

\begin{abstract}
The author proposes that there exists an ideological or paradoxical element in Chilean documentary film from the 1903-33 periods. This element refers to the fact that films attempt to recognize Chile's material and institutional modernity -particularly in the capital, Santiago, and some other industrial settlements- while depicting dramatic and public sites unpopulated.

Keywords: Chilean documentary film, modernity, unpopulatedness.
\end{abstract}

\footnotetext{
* Instituto de Estética, Facultad de Filosofía, Pontificia Universidad Católica de Chile. Santiago, Chile. Correo electrónico: pcorro@uc.cl

Artículo recibido el 08 de enero de 2015. Aceptado el 18 de junio de 2015.
} 
La obra de 1932 de Ernst Jünger, El trabajador, nos servirá para concebir a la masa, sus espacios, y su representación técnica y dinámica en el contexto chileno de las primeras tres décadas del siglo pasado. Sus imágenes, que invocamos como elementos de juicio, ofrecen ideológicamente la ventaja de la relatividad mimética de todas las modernidades y de sus formas y la desventaja de la abrumadora distancia geográfica y cultural, material, de Chile respecto de Occidente.

Dice el filósofo:

Cualquiera que sea el sitio en que nos topemos con la masa, resulta imposible no ver que está comenzando a ser invadida por una estructura diferente. La masa se ofrece a la percepción en bandas, mallas, cadenas y cintas de rostros que pasan rápidamente a nuestro lado con la velocidad del rayo; también se muestra en columnas de hormigas cuyo movimiento de avance no está ya sujeto al arbitrio de cada cual, sino a una disciplina automática (Jünger, 1990: 100).

El despoblamiento al que nos referiremos es el de los espacios urbanos, santiaguinos, y el de algunos emplazamientos industriales, mineros, de la zona central. Tales estructuras, como edificios, maquinarias, son los referentes iconográficos de modernidad, emplazamientos que la atención cinematográfica documental presenta o administra paradojalmente desprovistos de masas ciudadanas o trabajadoras. Al respecto, la sugerente observación de Jünger sobre una estructura que la percepción contemporánea siempre advierte invadiendo a la masa es en estos filmes por revisar la de los espacios renovados del Santiago moderno. A saber, los edificios del primer Centenario de Chile y sus emplazamientos contiguos, más o menos racionalizados, las estructuras del yacimiento cuprífero El Teniente y de la ciudad minera Sewell en 1919, que en circunstancias retóricas de su forzada presencia casi vacía corresponden a potenciales formas invasoras, a módulos, moldes, de masa en suspenso, segregadas provisoriamente del espacio visible en pos de un efecto dramático e ideológico. Ahora bien, puesto que la percepción que corresponde a nuestro análisis cultural está mediada por el aparato cinematográfico, él mismo, o sea la cámara, con sus esquematismos formales, pero también a través de la actitud documental, con sus creencias narrativas, mitologías epistemológicas y de la información, corresponde también a estructuras diferentes que invaden la forma de la masa, su capacidad de completar orgánicamente el espacio que aspira a desbordar. En tal caso el registro documental de lo moderno local despoblado o lleno también representa un diálogo o la tensión retórica de estructuras invasivas o lo que puede ser lo mismo, de estructuras formativas.

Antes de acreditar que el cine documental chileno identificó convencional y regularmente en sus primeros gestos locales muchedumbres urbanas, conjuntos numerosos de pobladores congregados en espacios citadinos y rurales, festivos, 
fúnebres y productivos, impulso que refuerza el principio de anomalía que entraña nuestra observación sobre registros de emplazamientos locales modernos despoblados, consideremos dos argumentos del historiador Stefan Rinke, sobre la posibilidad iconográfica y conceptual de la masa chilena en su libro Cultura de masas: Reforma y nacionalismo en Chile, 1910-1931. Son argumentos cualitativos y cuantitativos para figurar localmente aquel vertiginoso crecimiento poblacional, como dinámica moderna y reflejo de ese atributo dramático que Elías Canetti le atribuye a la masa en su obra Masa y Poder (2000), el de crecer para seguir siendo, pero también para cifrar la modernidad como integración de muchedumbre y medio de comunicación. El dato cuantitativo gráfico que expone Rinke es que en Santiago "el número de habitantes aumentó a más del doble, cerca de trescientos treinta mil en 1907 a más de setecientos mil en 1930, con un crecimiento correspondiente en el área metropolitana" (2002: 33). El cualitativo, es la imagen del público que se congregó en el centro de Santiago a escuchar la transmisión radial del match de box entre el campeón local Ángel Firpo y el estadounidense Jack Dempsey: "En la tarde del 14 de septiembre de 1923, una multitud de más de dos mil chilenos, en su mayoría pertenecientes a la clase media, se reunió frente al edificio del periódico La Nación, ubicado en el distrito financiero de Santiago" (2002: 21). Sobre el match como fundamento de la concurrencia Rinke precisa que los púgiles "disputaban la copa mundial de peso pesado en Nueva York en un torneo que sería objeto de la primera transmisión radial en vivo de la historia chilena" (2002: 21).

Rinke resalta que el evento de esa memorable noche reúne un conjunto de innovaciones, índices de modernidad que son tales no solo por sí mismos sino por su convergencia: una audiencia masiva, un suceso transmitido por el medio de comunicación más moderno de la época, el tráfico automovilístico urbano, la iluminación nocturna del centro de Santiago.

El plano cuadrado frente al edificio del diario La Nación, la potencia convergente de los posibles altoparlantes de la radio, la disruptiva presencia estática o dinámica de los automóviles y el poder aglutinante o disolvente de las luminarias y las sombras nocturnas entreveradas, son configuradores en distinto grado de esa masa de dos mil aficionados al box pero especialmente son para la percepción moderna, enervada por las señales de lo múltiple, las estructuras de lo diferente que la invaden: el intangible rayo o manto de luz eléctrica; las ondas radiales articulando en lo abierto voces y ruidos simultáneos de un espacio remoto, también abierto, pero aún más intenso y poblado; las contigüidades mecánicas niveladas con los hombres en su derecho al espacio, disputándoselo; los cercos de cemento; las nuevas elevaciones de piedra y fierro, que a través del sentido de la altura, y cobijando el vuelo de la luz eléctrica y de la presencia radial, le recuerdan a la masa su relatividad dramática e ideológica con lo aéreo (Gumbrecht, 2004). 
Ahora bien, en cuanto a la acreditación de la comparecencia cinematográfica documental de una masa chilena, de acuerdo a la disponibilidad actual de materiales de archivo, esta comienza temprano, en 1903, con la vista fílmica $U n$ paseo a Playa Ancha rodada por A. Massonier. Con el arcaico documental Festejos en el Parque Cousiño (1910), filme anónimo que registra la dimensión popular y pública de las celebraciones del Centenario de la República, comparten la producción escénica de un sentido de muchedumbre a través de la disposición de cercanía entre el registro y los conjuntos numerosos de gente enfiestada. Si bien los colores locales de los bailes típicos, los jinetes, los bebedores de vino en enormes botellas, o la exhibición de platos típicos, no constituyen argumentos materiales de modernidad, eventualmente de exotismo, la obstinada, evidente disposición de todo ello para el registro de la cámara, la artificiosa orientación espacial de lo supuestamente aleatorio festivo para la composición del cuadro fílmico constituye un gesto moderno, una conciencia técnica de espectacularización de la vida.

Congregaciones mayores ofrece la historia documental del cine chileno en los proto-filmes Gran revista militar en el Parque Cousiño (1910), Revista naval en Valparaíso (1910), ambas, presuntamente del realizador Arturo Larraín Lecaros, y en el documental institucional Actividades del Liceo Valentín Letelier (1930), de realizador no identificado.

En los primeros dos casos la muchedumbre asume dos formas: una con protagonismo escénico, la de los militares, oficiales y tropas que desfilan, oficiales y marinería que asoman y delinean los perfiles de los barcos engalanados formando ornamentales figuras humanas y otra, la del público espectador que se congrega en las periferias de la elipse del parque o en el muelle del puerto de Valparaíso para, a través de la mirada, elevar a apoteosis el despliegue de fuerzas del Estado organizado.

Canetti, según sus taxonomías de la muchedumbre en Masa y Poder, diría que los observadores son masa de "descarga", aquellos individuos que han vencido el miedo al contacto del otro justamente realizándolo en la plenitud de la congregación, en este caso, festiva, ideológica y dramáticamente unificadora, en cambio, las fuerzas armadas protagónicas constituirían lo que él llama "cristales de masa”, el residuo contemporáneo de una otrora turba beligerante que sacrificó su crecimiento espontáneo por la voluntad de durar.

Sus geometrías de desfile y composiciones plásticas humanas en los barcos son acreditaciones del estatuto delineado, geométrico de cristal, y su consistencia, que se manifiesta en el alineamiento y perfecto compás dinámico, concurre en pos de la idea de la trascendencia del Estado-Nación que entonces cumple 100 años.

En el cortometraje Revista naval en Valparaiso, a la disposición moderna de los actos públicos, sensible a la actividad de un registro visual técnico, hay que sumarle la presencia monumental, persuasiva, retórica, de los vapores de guerra y de las gigantescas grúas portuarias. 
En el sentido de la coexistencia asistencial entre recursividad técnica y cristales de masas incluimos la referencia al filme muy posterior Actividades del Liceo Valentín Letelier, donde los conjuntos hacinados de estudiantes de ese establecimiento público de excelencia, obedecen con desbordes carnavalescos ocasionales el guion institucional y fílmico de la disciplina física, formación científica, normatividad intelectual y determinación ética.

En la película, los poblados conjuntos estudiantiles masculinos, rodean a los maestros que manipulan instrumentos de ciencias para diseccionar conejos y ranas en los espacios altos, ruinosos y mal iluminados de la que fuera la quinta del ministro Diego Portales. La alternancia de juegos, pruebas físicas, esquemas gimnásticos, trabajos de gabinete científico, y juramento del "decálogo liceano", constituyen para el programa documental el itinerario abreviado de la formación de un cristal de masa, el del "estudiante", precedente del hombre ilustrado.

En las actualidades cinematográficas Los funerales del Presidente Montt (1911), realizada por Julio Cheveney, Funeral de Luis Emilio Recabarren (1924), de Carlos Pellegrín Celedón, y en el documental de Armando Rojas, fundador y operador del Instituto de Cinematografía Educativa, ICE, Santiago 1933 (1933), comparecen las muchedumbres que faltan en los documentales de la modernidad despoblada que nos interesa. En los funerales de Pedro Montt, que cinematográficamente se narran como el viaje de un muerto por mar y tierra, por barco, tren a vapor, carroza tirada por caballos, y finalmente por pulso de hombre ${ }^{1}$, las masas asumen esa diversidad apariencial estamentaria propia del siglo XIX, que según Jünger desaparece en el siglo XX con la uniformidad del traje burgués, que sería en el vestuario el reflejo de la uniformidad de máscara de los rostros modernos. Como señala Jünger, bandas, mallas, filas de hormigas-personas, flanquean en las estaciones del valle del Aconcagua, el avance frontal de los dos trenes, el que lleva el cadáver de Montt y el que lo filma, que desde el fuera de campo anterior ilustra mejor el protagonismo de la velocidad mecánica como dato físico moderno, que se opone al estatuto de inerte del pasajero, a la pompa decimonónica de la negra carroza seńorial y a los trajes de la clase alta que desfila, protagonistas del próximo declive de la aristocracia gobernante.

Ahora bien, no hay masa mayor, más densa en el cine documental chileno que la que presenta el filme Funeral de Luis Emilio Recabarren², multitud que

\footnotetext{
${ }^{1}$ Sombrío relato de aventuras que nos recuerda tanto la cinética obertura dramática del cuento de Franz Kafka El cazador Gracchus (1917), como el interés persistente del cine por la marcha de los muertos, dinamismo paradojal que, por ejemplo, acredita el cine alemán a través de sus dos versiones del vampiro Nosferatu, el de Friedrich Wilhelm Murnau, de 1922, y el de Werner Herzog, de 1979.

${ }^{2}$ Luis Emilio Recabarren (1876-1924), obrero tipográfico, periodista, y fundador en 1912 del Partido Obrero Socialista de Chile que se convirtió en 1922 en el Partido Comunista de Chile.
} 
llena de bote en bote las calles, las avenidas, y requiere de un plano general en ángulo de picado para ser dimensionada, para graficar composicionalmente su elocuencia. Solo recordamos una multitud semejante en el documental de Claudio Di Girolamo, Andrés de la Victoria (1985), otro filme fúnebre: ese cortejo de pobladores que peregrina desde el sur, desde la Población La Victoria, para honrar en la Catedral de Santiago al sacerdote André Jarlan, asesinado por Carabineros de Chile durante una jornada de protesta, y que desde el campanario se ve repletando la calle Ahumada hasta la Plaza de Armas.

La masa del Funeral de Luis Emilio Recabarren es, a nivel de uniformidad de las apariencias, plenamente moderna, los millares de trabajadores de los más diversos sindicatos aparecen con idéntico traje burgués masculino, los sombreros de paja tipo "hallulla", le imprimen al cuerpo lento de la multitud el motivo aun más monstruoso de una suerte de miles de ojos. Tan abrumadora es esta masa que fluye desde las calles a las avenidas como un "río", uno de los motivos de la iconografía poética de la multitud que propone Canetti, que no es posible sentir la interacción individualizada entre figurantes y cámara y tampoco se hace posible advertir con protagonismo otro elemento técnico, como autos o postes de alumbrado, de manera tal que la modernidad se impone dramáticamente en el filme solo por la convergencia dominante de masividad, uniformidad y lentitud humana, y apatía del registro.

La pretensión documental de lo moderno en Santiago 1933 (1933) es más dinámica que poblada, el dinamismo es una prueba que se encarga a la presencia de automóviles y tranvías, que, honestamente, no convencen en número, y que se solicita también al trabajo mecánico, renovador del espacio urbano, a locomotoras, grúas mecánicas y montacargas de edificios modernistas en construcción del destacado arquitecto Luciano Kulczewski y del gabinete Smith y Solar. La presencia de las masas urbanas se formaliza en dos esquemas de planificación, uno, el de los primeros planos rasantes de piernas de transeúntes que corresponden efectivamente a esa fila de hormigas de que hablaba Jünger y que ya en la década del treinta era un definido tópico fílmico, el otro, el de la ampliación de esos flujos registrados en plano general picado y figurando el riesgo de las esquinas urbanas, de las calles Estado con Compañía, Ahumada con Compañía, encrucijadas de posibles colisiones entre hombres, y entre gente y vehículos, riesgo dinámico propio de lo urbano según Walter Benjamin (1936), posibilidad de choque.

Un poco antes, en 1925, postulando la existencia de otros centros geográfico-políticos, núcleos de urbanidad, Juan Pérez Berrocal en el filme Canta y no llores corazón, y, precisamente en 1933, el sacerdote salesiano, Alberto de Agostini, en Tierras Magallánicas, presentaron las muchedumbres citadinas de las ciudades de Concepción y Punta Arenas girando en sus respectivas plazas de armas, afirmando su modernidad de siglo XX por la acreditación mecánica-fílmica de su 
hacinamiento; pero también haciendo el cuadro cinematográfico de la ritualidad pueblerina decimonónica que invierte el tiempo viéndose a sí misma en vivo y en directo. Tales imágenes son ante todo registros de transiciones en los modos modernos de autocontemplarse.

En Santiago 1933, de Armando Rojas, la visión poética moderna del registro documental se expresa a través de la elevación diurna mecánica de los montacargas de las edificaciones, también como altura nocturna de irradiante retórica del consumo en los neones de la calle Bandera, pruebas de la rentabilidad de la noche vencida como tiempo laborable. El efecto de imagen caleidoscópica, donde mediante una argucia del lente y del montaje con sobreimpresiones, en un mismo plano se presentan reunidos y convergentes los flujos mecánicos de autos y trenes con los flujos humanos de los transeúntes, es también una metáfora plástica, óptica, del propósito ilustrado de la visión o control simultáneo de todos los espacios. Santiago 1933, ya lo hemos señalado en textos previos ${ }^{3}$, contiene, aunque sin correlato histórico productivo, correlato económico fabril, los elementos dramáticos, icónicos y retóricos de cualquier "sinfonía de ciudad" de la segunda década del siglo XX, esto es, los flujos mecánicos y orgánicos, reflejos y conjugados, el deslumbramiento eléctrico de la noche, la caracterización óptica del control a distancia y de la figuración de la actividad simultánea como conciencia interesada de actividades remotas en dependencia potencial. La presencia cifrada de masas, de flujos humanos en el filme, en el modo de lo bastante como para graficar la muchedumbre como un lugar común de lo urbano, depende en su restricción no tanto de las condiciones efectivas de población en el Santiago de la cuarta década, sino del ensayo del lenguaje documental de lo moderno plástico que Armando Rojas articula con las porciones gráficas de trabajo, movimiento y mecanismo. Un acertado encadenamiento causal, y en este caso fílmico, de analogías que Jünger confirma en El trabajador, sosteniendo que:

En el movimiento apunta el lenguaje propio del trabajo, un lenguaje que es primitivo y también envolvente, un lenguaje que se afana en trasladarse a todas las cosas que pueden ser pensadas, sentidas, queridas. La pregunta por la esencia de ese lenguaje, pregunta que sin duda suscitará en el observador, insinúa como respuesta la siguiente: tal esencia hay que buscarla en lo mecánico.

\footnotetext{
${ }^{3}$ En el artículo "Sinfonías de ciudad en el cine chileno: Imágenes de modernidad, efectos de luz". Enfoque al cine chileno en dos siglos. En Villarroel, Mónica (Ed.), Santiago de Chile: LOM Ediciones y Centro Cultural la Moneda, 2013.
} 
Antes que Día de Organillos (1959), de Sergio Bravo, segunda sinfonía de ciudad del cine chileno, Santiago 1933, es el primer filme chileno mecánico.

En cuanto a los documentales de la modernidad despoblada, el corpus referencial lo constituyen prioritariamente y en orden cronológico las películas: Volación (1911), anónima; El mineral El Teniente (1919), realizada por el operador Salvador Giambasttiani para la Braden Cooper Company; Imágenes reencontradas de Santiago de los años 20, sin autor identificado; y El Cerro Santa Lucía, 1929, realizada por el ya referido Instituto de Cinematografía Educativa, ICE, y su director, Armando Rojas.

En orden de contradicción dramática entre emplazamientos modernos y presencia ciudadana, la película que ofrece el índice más alto es Imágenes reencontradas de Santiago de los años 20. El filme, realizado probablemente por una instancia gubernamental para difundir la modernidad de Santiago, reforzada materialmente por las obras del Centenario, en nuestros consulados en el extranjero, hace un inventario de los hitos materiales de un Estado occidental desarrollado. En ese muestrario, siempre en planos generales cortos de cada edificio, procurando segregar el espacio contiguo que probablemente ocupa un inmueble colonial, destacan por su soledad: el Palacio de La Moneda, la Bolsa, la Biblioteca Nacional, la Escuela de Ingeniería de la Universidad de Chile, el Banco Central y el Museo Nacional, emplazado entonces en la Quinta Normal. Las leyendas en francés de los carteles argumentan con insistencia que en el contexto de América Latina tales instituciones resultan ejemplares. Toda la población que resulta ausente en esos entornos céntricos, al final del filme, pareciera congregada en un desfile de automóviles enfiestados en el contexto de un carnaval de primavera.

En el artículo Sinfonías de ciudad en el cine chileno: imágenes de modernidad, efectos de luz (2013), propusimos que la segregación de los pobladores, de las masas, de esta representación, se debe probablemente a que su aspecto no se condice con la modernidad que miméticamente pretenden los edificios, a un desajuste entre su apariencia física y atuendo con los de un sujeto fílmico occidental y contemporáneo. Ahora agregamos que si relacionamos en este documental las evidencias dramáticas de una masa únicamente presente en los actos festivos con el despoblamiento de los edificios de la razón productiva, surge una doctrina que a nivel de la representación confina la actividad funcional y sus agentes dramáticos en los interiores institucionales, y que en relación con la ultra-modernidad del registro cinematográfico en la conciencia material de la segunda década del siglo pasado, presenta las sedes del trabajo en el reposo inaugural, en ese estado de pura potencia de actividad, o como sistemas autosuficientes, casi automáticos, hipótesis dramática debida acaso a una licencia futurista del medio de registro.

La soledad complementaria del parque urbano, reserva ordenada de naturaleza, resemantización romántica del cerro "Huelén" o "dolor", en lengua mapuche, 
fortaleza guerrera, cementerio de los protestantes "desterrados del cielo y de la tierra" hasta fines del siglo XIX, se presenta en el documental El Cerro Santa Lucia (1929), de Armando Rojas. La elevación de la perspectiva citadina en el cine es siempre un indicador de modernidad material, como afirmación de la victoria constructiva respecto del peso y la gravedad o como visión de dominio y ordenamiento policial. En este documental del ICE, las fracciones panorámicas, que desde la cumbre del cerro había ensayado el filme anterior, se perfeccionan hasta la plenitud de los 360 grados. La ciudad baja, pueblerina, que revela esa vista, no se condice con la hipótesis argumental del filme que a través de sus carteles establece una oposición entre el oasis vacío del cerro, sus caminos misteriosos, el observatorio astronómico, las fuentes de agua sin observadores, todos motivos de "videncia", y la agitación y suciedad del ambiente urbano. Mientras las leyendas refieren que "abajo la ciudad sigue la vida agitada" y hablan del "aire viciado de las calles", el objetivo de Armando Rojas se esfuerza por encuadrar sin éxito alguna esquina céntrica que acredite con autos y gentes, tales lugares comunes de lo urbano.

Stefan Rinke (2000) y Bernardo Subercaseaux (2004), en sus diversas aproximaciones a la génesis de la cultura de masas en el siglo XX chileno, como asunto de tensión de ideas e imágenes, destacan la presencia del aeroplano en los cielos narrativos locales como forma de caracterización técnica del vuelo poético ascendente o descendente, diurno o nocturno, que cierra una época pero que especialmente abre otra. El espacio aéreo rural, pero también urbano, es una dimensión despoblada, por lo mismo propicia a las efusiones del espíritu. En el filme Volación, que registra el vuelo del biplano Voisin, piloteado por el español Antonio Ruiz, sobre el llano del Hipódromo Chile, vuelo que según el periódico El Ferrocarril ${ }^{4}$ habría concluido en desastre, cosa que el documental no muestra, son pocos los figurantes que acompañan al piloto en las maniobras de ubicación y despegue de la nave. Pese a que la Dirección de Aeronáutica civil señala que se trataría de uno de los primeros vuelos sobre Santiago, no hay multitudes, ni agitaciones festivas que rodeen el acontecimiento 5 . Sin embargo, sospechamos que la masa espectatorial sí estuvo en el evento pero quedó fuera de campo, en el lado del fuera de campo anterior en la posición de proscenio de las graderías. El despegue fue dispuesto en la cancha interior que circunda la pista, y a ese espacio reservado para la proeza técnica solo pudo entrar el operador fílmico anónimo. Puesto entre el despegue y la posición de las masas, el aparato fílmico se expresa positivamente como un mediador, y aunque la puesta en escena procure brindarle al vuelo del biplano la dignidad espiritual del vacío, de la soledad de lo aéreo,

\footnotetext{
${ }^{4}$ Edición del 23 de marzo de 1911, pp. 1 - 5.

${ }^{5}$ Como sí ocurre por ejemplo en el relato de asunto semejante de Franz Kafka, Los aeroplanos de Brescia, 1909.
} 
los saludos del piloto más hacia el público en el antecampo que hacia el registro, implican a la masa de manera implícita.

El último documental de modernidades despobladas, o relativamente despobladas, al que nos referiremos, se aleja del espacio urbano pero corresponde a esos emplazamientos rurales, espacios naturales donde la modernidad se instala a través de estructuras técnicas industriales de explotación, en este caso de yacimientos mineros, El mineral El Teniente, de Salvador Giambasttiani. Este filme corporativo presenta las instalaciones de extracción y elaboración del cobre chileno cordillerano por la Braden Cooper Company en el yacimiento que da nombre al filme, en la localidad precordillerana de Coya, pero especialmente en la ciudad-campamento de Sewell. A través de la modernidad representada en las grandes estructuras de elaboración del mineral, grandes edificaciones que humean, de los puentes mecánicos, de los ferrocarriles que mueven a la población y al mineral, y de los edificios de viviendas que escalan la montaña hasta configurar una especie de pirámide moderna, se prueba aquello que sostiene Stefan Rinke en Cultura de masas reforma y nacionalismo:

Al comenzar el siglo XX, un número significativo de chilenos encontró una forma especial de modernidad, cuando inversionistas estadounidenses montaron en la cordillera de Los Andes y en el desierto de Atacama gigantescas empresas mineras, que ocupaban la más moderna tecnología de la época (81).

En 1918 indica el historiador que la población de la ciudad minera de Sewell era más que considerable, pensando en que se trata de un lugar remoto y de clima inhóspito: catorce mil habitantes. Sin embargo, en el documental, que señala espacios de faenas, de estructuras de circulación de los productos, vías de comunicación, zonas de vivienda, de administración, y de vida social, serie de hitos narrativos de un documental por encargo institucional, los conjuntos humanos no abundan. En el filme la población apenas se concentran en la estación de trenes, como afirmando el espacio de conexión con la urbe remota, y la conexión misma a través de un recurso técnico como hecho moderno, o se agolpan especialmente, en los espacios de juegos y fiestas que la población chilena, la casta de los trabajadores, fondo estamental de esa sociedad regida por anglosajones, anima, seguramente, por encargo del director de la película. Donde particularmente sorprende la escasez de figurantes es en las grandes estructuras mineras, en las salas de máquinas, en los llanos de descarga de residuos o de relleno de material. Si bien en los planos generales los galpones, las maestranzas, las usinas, aparecen humeando, en los espacios de las entrañas mecánicas aparecen pocos trabajadores y los presentes simulan trabajar: martillan sin sentido un riel, deslizan sin pintura una brocha por un muro, serruchan sin objeto un madero, incluso un obrero juega, como en una rutina de slapstick, a golpearle a otro la cabeza con un gran martillo. 
Nuevamente podríamos sostener que la conciencia documental chilena de lo moderno prefiere prescindir de las masas trabajadoras y figurar los activos espacios mecanizados como entidades "autopoiéticas", autónomas. Ese autogobierno del mecanismo productivo, que hay que relacionar con la escena de la pantomima del trabajo, es reforzado por el silencio técnico del filme, por aquel mutismo del formato, propio de la segunda década del cine, que se mantiene hasta mediados del treinta. El silencio de la imagen de la pesada maquinaria moderna, y de la actividad en reposo despoblada, le confiere a su ejemplaridad de lo técnico como motivo cultural invasivo una levedad dramática, una amabilidad de lo que no perturba ni lo social ni al paisaje natural. Conviene allegar a estas ideas las observaciones de Jünger en 1932 sobre las pretensiones de levedad de la escena maquinal y el grado de percepción de su ruido:

Un orden meticuloso imprime el sello de la conciencia, del trabajo preciso del entendimiento, a esa maquinaria que se desliza y gira y que asemeja al funcionamiento de un reloj o de un molino; el todo aparece al mismo tiempo, sin embargo, como algo parecido a un juego, en el sentido de un pasatiempo automático. Esta impresión se hace más intensa a ciertas horas en que el movimiento alcanza un grado de orgía que aturde y extenúa los sentidos. Las pesadas cargas que aquí son vencidas escaparían tal vez a la percepción si unos sonidos silbantes y ululantes, en los que se expresa de manera inmediata una imperiosa amenaza de muerte, no llamara su atención sobre el grado de las fuerzas mecánicas que aquí están operando $(97,98)$.

Queda pendiente el estudio de la relación estética e ideológica que la ausencia del sonido del mundo, como efecto de una limitación de la técnica cinematográfica, mantiene con la omisión o la figuración apacible de la masa en los documentales chilenos de comienzos del siglo XX. También debiera motivar un estudio futuro la evidencia que en la mayoría de los filmes señalados como acreditadores de masas chilenas, nos referimos particularmente a Festejos en el Parque Cousiño, Gran revista militar en el Parque Cousiño, Revista naval en Valparaíso, Los Funerales del Presidente Montt, Funeral de Luis Emilio Recabarren y Santiago 1933, la presencia femenina como ciudadanas, agentes políticas, o población trabajadora casi no figura. En Festejos del Parque Cousiño aparecen representadas como bailadoras de cueca, por lo tanto, sometidas a una función ornamental, y en las exequias de Recabarren, como integrantes de la familia del difunto, es decir, como relativas a su intimidad. A pesar de que este filme presenta una movilización pública, esas mujeres expuestas en el plano general corto de los familiares, sin acreditación de sus identidades en los carteles, se mantienen narrativamente en el círculo de lo íntimo, de lo interior, que comporta el tópico de la filiación. Al respecto, conviene señalar que en las partículas 
de población que aparecen en los filmes despoblados, también las mujeres figuran en una proporción ínfima respecto de los hombres, por ejemplo de los mineros, funcionarios, niños trabajadores y niños jugando que presenta El Mineral El Teniente. Nuevamente bajo la figura dramática documental de la bailadora de cueca, las mujeres aparecen en esta película con sentido de ornamento, y también sujetas a la misma función de adorno, o peor aún, de referente espacial y de figura dinámica que asegura la duración del plano, resulta la pareja de damas que atraviesa la calle Blanco, el gran plano general vacío de la Escuela de Ingeniería de la Universidad de Chile en Imágenes reencontradas de Santiago de los años 20. De acuerdo a estas evidencias nuestra modernidad en las imágenes fílmicas de las primeras décadas del siglo XX no solo se presenta despoblada, sino que además su escasa o confinada población propuesta es masculina, identificando casi absolutamente los discursos de la épica nacional y de la sedes del trabajo con la presencia de los hombres ${ }^{6}$.

Para terminar, y a modo de hipótesis sobre la figuración restrictiva de los contingentes trabajadores en los modernos complejos cupríferos de El Teniente y Sewell en el filme de Giambasttiani, recordamos con los antecedentes de Stefan Rinke que en 1911 hubo una huelga en esos enclaves mineros, y que en el momento mismo de la realización del documental, se intensificaban los conflictos entre la empresa extranjera y los trabajadores, que desembocaron en la gran huelga de 1919. La conjetura es que la masa falta en la escena para evitar contribuir con la legitimación dramática cinematográfica a su sentido de cuerpo y de autoconciencia épica.

Para cerrar estas digresiones sobre la figuración variable y por lo mismo problemática de las poblaciones humanas, de las masas, en las representaciones documentales chilenas de lo moderno en las primeras tres décadas del siglo XX dejamos resonando con el valor de su ambigüedad una frase de Ernst Jünger, en el parágrafo 31 de El trabajador: "Para llegar a ver al ser humano se necesita ciertamente un esfuerzo especial $-\mathrm{y}$ esto no deja de ser raro en una edad en la que el ser humano aparece en masse" (99).

\footnotetext{
${ }^{6}$ Para verificar una correspondencia entre esta relativa marginación dramática en los discursos no ficcionales modernizantes de la nación y el estado chileno y un eventual proporcional menor contingente femenino en la clase obrera, en los sectores profesionales, funcionarios y estudiantiles del país durante las primeras tres décadas del siglo XX, conviene revisar el tomo IV de la Historia Contemporánea de Chile: Hombría y feminidad (2002), de Gabriel Salazar y Julio Pinto, en particular el capítulo dos "Historia y feminidad en Chile. Siglos XIX y XX".
} 


\section{REFERENCIAS}

Actividades del Liceo Valentín Letelier (película). Producción, ECA Films, 1930. (13 min., $55 \mathrm{seg}) 16 \mathrm{~mm} ., \mathrm{b} / \mathrm{n}$, silente.

Andrés de La Victoria (película). Dirección, Claudio Di Girolamo, 1985. (55 min.) video, color.

Benjamin, Walter. La obra de arte en la era de su reproductibilidad técnica (URTEXT). México D.F.: Itaca, 2003.

Canetti, Elías. Masa y poder. Madrid: Alianza, 2000.

Canta y no llores corazón (película). Dirección, Juan Pérez Berrocal, 1925. (50 min.) $35 \mathrm{~mm} ., \mathrm{b} / \mathrm{n}$, silente.

Corro, Pablo. "Sinfonías de ciudad en el cine chileno: Imágenes de modernidad, efectos de luz". En Mónica Villarroel (Ed.), Enfoque al cine chileno en dos siglos. Santiago, Chile: LOM Ediciones y Centro Cultural la Moneda, (2013): 23-32.

Día de organillos (película). Dirección, Sergio Bravo, (1959). (20 min.) 16 mm., b/n.

El Cerro Santa Lucía (película). Dirección, Armando Rojas, (1929). (10 min.) 16 mm., sepia, silente.

El Mineral El Teniente (película). Dirección, Salvador Giambastiani, (1919). 16 $\mathrm{mm} ., \mathrm{b} / \mathrm{n}$, silente.

Festejos en el Parque Cousiño (película). Dirección, producción, no identificada, (1910). (2 min. 3 seg.), $35 \mathrm{~mm} ., \mathrm{b} / \mathrm{n}$, silente.

Funeral de Luis Emilio Recabarren (película). Dirección, Carlos Pellegrín Celedón, (1924). (8 min, $8 \mathrm{seg}) 16 \mathrm{~mm} ., \mathrm{b} / \mathrm{n}$, silente.

Gran revista militar en el Parque Cousiño (película). Dirección, presumiblemente Arturo Larraín Lecaros, (1910). (2 min. 43. Seg) 35 mm., b/n, silente.

Imágenes reencontradas de Santiago de los años 20 (película). Dirección, producción, no identificados, (años 20). (10 min.) $35 \mathrm{~mm}$., b/n, silente con intertítulos. 
Jünger, Ernst. El trabajador. Barcelona: Tusquets, 1990.

Los funerales del Presidente Montt (película). Dirección, Julio Cheveney, (1911). (9 min. 35 seg.) $35 \mathrm{~mm}$. , b/n, silente.

Revista naval en Valparaíso (película). Dirección, presumiblemente Arturo Larraín Lecaros, (1910). (1 min. $30 \mathrm{seg}$.) $35 \mathrm{~mm}, \mathrm{~b} / \mathrm{n}$, silente.

Rinke, Stefan. Cultura de masas: Reforma y nacionalismo en Chile, 1910-1931. Santiago, Chile: Dibam. 2002.

Santiago 1933 (película). Dirección, Armando Rojas Castro (1933). (10 min. 11 seg.) $16 \mathrm{~mm} ., \mathrm{b} / \mathrm{n}$, silente.

Subercaseaux, Bernardo. Historia de las ideas y de la cultura en Chile. Tomo III. El centenario y las vanguardias. Santiago, Chile: Editorial Universitaria, 2004.

Tierras Magallánicas (película). Dirección, Alberto María de Agostini, sacerdote salesiano (1933). (50 min.) $35 \mathrm{~mm}, \mathrm{~b} / \mathrm{n}$, silente.

Un paseo a Playa Ancha (película). Dirección, A. Massonier, (1903). (2 min. 17 seg.) $35 \mathrm{~mm} ., \mathrm{b} / \mathrm{n}$, silente.

Volación (película). Dirección, producción, no identificados, (1911). (1 min 14 seg.) $35 \mathrm{~mm}, \mathrm{~b} / \mathrm{n}$, silente. 